\title{
The immunoreactivity of satellite glia of the spinal ganglia of rats treated with monosodium glutamate
}

\author{
Aleksandra Ewa Krawczyk, Jadwiga Jaworska-Adamu \\ University of Life Sciences, Faculty of Veterinary Medicine, \\ Department of Animal Anatomy and Histology, Lublin, Poland
}

Received March 30, 2016

Accepted December 19, 2016

\begin{abstract}
Satellite glia of the peripheral nervous system ganglia provide metabolic protection to the neurons. The aim of this study was to determine the effects of monosodium glutamate administered parenterally to rats on the expression of glial fibrillary acidic protein, S-100 $\beta$ protein and Ki-67 antigen in the satellite glial cells. Adult, 60-day-old male rats received monosodium glutamate at two doses of $2 \mathrm{~g} / \mathrm{kg}$ b.w. (group 1) and $4 \mathrm{~g} / \mathrm{kg} \mathrm{b}$.w. (group 2) subcutaneously for 3 consecutive days. Animals in the control group (group C) were treated with corresponding doses of $0.9 \%$ sodium chloride. Immediately after euthanasia, spinal ganglia of the lumbar region were dissected. Immunohistochemical peroxidase anti-peroxidase reactions were performed on the sections containing the examined material using antibodies against glial fibrillary acidic protein, S-100 $\beta$ and Ki-67. Next, morphological and morphometric analyses of immunopositive and immunonegative glia were conducted. The data were presented as the mean number of cells with standard deviation. Significant differences were analysed using ANOVA $(P<0.05)$. In all 63-dayold rats, immunopositivity for the examined proteins glia was observed. Increased number of cells expressing glial fibrillary acidic protein was demonstrated in group 2, whereas the number of S-100 $\beta$-positive glia grew in the groups with the increasing doses of monosodium glutamate. The results indicate the early stage reactivity of glia in response to increased levels of glutamate in the extracellular space. These changes may be of a neuroprotective nature under the conditions of excitotoxicity induced by the action of this excitatory neurotransmitter.
\end{abstract}

Glial cells, immunohistochemistry, sodium salt of glutamic acid

Spinal ganglia of the peripheral nervous system are structures lying on the course of the nerve fibres that transmit sensory impulses from the periphery of the body to the central nervous system (Hanani 2005). Pseudounipolar neurons and satellite glia are located under a connective capsule which is formed by each spinal ganglion. Glial cells are flattened and have a number of intermeshing processes forming a tight sheath around almost every neuron. These glia control neuronal microenvironment by participating in ion homeostasis and metabolism of, among others, glutamate (Glu) which is one of the major excitatory neurotransmitters of the nervous system. In the sensory ganglia this amino acid is present in 30-70\% neurons (Nedergaard et al. 2002; Hanani 2005; Kung et al. 2013). Furthermore, glial sheath is a barrier to different blood compounds which can pass through the fenestrated capillaries present in the connective tissue mesh of the ganglia (Hanani 2005).

Monosodium glutamate (MSG) is a widespread chemical additive that improves food flavour. Experiments conducted on animals have shown that this compound has very low toxicity when applied orally. However, at high doses or when administrated parenterally, monosodium glutamate can be neurotoxic, leading to excitotoxic damage and even death of the nerve structures (Mallick 2007; Ganesan et al. 2013). These changes are accompanied by glial activation which seeks to compensate for changes in the environment immediately after the effect of the damaging agent, e.g. by adjusting the level of ions and

Address for correspondence:

Aleksandra Krawczyk

Department of Animal Anatomy and Histology

Faculty of Veterinary Medicine, University of Life Sciences

Akademicka 12, 20-033, Lublin, Poland

Phone: + 48 (81) 4456849

E-mail: aleksandra.krawczyk@up.lublin.pl

http://actavet.vfu.cz/ 
neurotransmitters (Nörenberg 1994). Within the next hours, early reactivity processes occur due to the modifications of the normal cell characteristics relative to the altered environmental conditions. This phase is manifested by reactive synthesis and increased expression of various proteins, e.g. the glial fibrillary acidic protein (GFAP) and the S-100ß protein (Eddleston and Mucke 1993; Stephenson and Byers 1995; Hanani 2005; Ohara et al 2009; Middeldorp and Hol 2011). In the last stage, permanent or long-term morphological and functional cellular changes were observed. During this period, hypertrophy of cellular bodies and processes and also increased glial proliferation were demonstrated (Nörenberg 1994). The phenomenon of excitotoxicity is associated with several diseases of the nervous system, e.g. epilepsy, stroke, ischaemia, Parkinson's disease, or Alzheimer's disease (Yuan et al. 2007; Bezprozvanny and Mattson 2008; Ganesan et al. 2013). Therefore, parenterally administered MSG is often used in animal experimental models of many neurological disorders which allows for a better understanding of their pathomechanisms (Ganesan et al. 2013).

Until now, reactive behaviour of the satellite glia of ganglia in response to the increased concentration of Glu in the extracellular space was never determined. The aim of the study was to investigate the immunoreactivity of GFAP, S-100 $\beta$ and Ki-67 in glial satellite cells after parenteral administration of MSG.

\section{Materials and Methods}

Animals and preliminary examination procedure

The experiment was performed on fifteen 60-day-old male Wistar rats. During the whole period of the experiment, the animals were kept in cages at a room temperature between $20-22{ }^{\circ} \mathrm{C}$ and $60 \%$ humidity, in a $12 \mathrm{~h}: 12 \mathrm{~h} \mathrm{light/dark} \mathrm{cycle.} \mathrm{The} \mathrm{rats} \mathrm{had} \mathrm{free} \mathrm{access} \mathrm{to} \mathrm{fodder} \mathrm{and} \mathrm{water,} \mathrm{and} \mathrm{stress} \mathrm{factors} \mathrm{were} \mathrm{reduced} \mathrm{to}$ a minimum. The study was approved by the Second Local Ethics Committee for Experiments on Animals in Lublin (7/2011). Animals were randomly divided into three groups. The two experimental groups received monosodium glutamate (MSG) at doses of $2 \mathrm{~g} / \mathrm{kg} \mathrm{b.w.} \mathrm{(group} \mathrm{1)} \mathrm{and} 4 \mathrm{~g} / \mathrm{kg} \mathrm{b.w.} \mathrm{(group} \mathrm{2)} \mathrm{subcutaneously} \mathrm{for} 3$ consecutive days. The control group (C) received the corresponding volume of saline. Twenty-four hours after the last injection, the rats were euthanised and the lumbar sensory ganglia (L1-L4) were dissected. The material was fixed in buffered $10 \%$ formalin $\left(\mathrm{pH}=7.0\right.$, temp. $\left.4^{\circ} \mathrm{C}, 12 \mathrm{~h}\right)$ and embedded in paraffin blocks by a routine histological technique. Afterwards, $4 \mu \mathrm{m}$ thick sections containing the sensory ganglia were obtained using a microtome.

\section{Indirect staining by immunohistochemistry}

Indirect peroxidase anti-peroxidase (PAP) immunohistochemical reactions were carried out on deparaffinised and hydrated sections of the ganglia derived from each animal. All antibodies and reagents were obtained from Sigma-Aldrich (St. Louis, Missouri, USA) and were diluted in TBS (Tris Buffered Saline; T5030) pH = 7.6 in accordance with the manufacturer's instructions. In order to retrieve the antigen, each third slide was heated in $0.01 \mathrm{M}$ citrate buffer solution $(\mathrm{pH}=6.0)$ in a microwave oven in three 5-min cycles. Afterwards, all sections were treated with $3 \% \mathrm{H}_{2} \mathrm{O}_{2}(30 \mathrm{~min}$ at room temperature) and subsequently with normal goat serum for 20 min at room temperature (G9023; 1:10). Next, an incubation of sections at $4{ }^{\circ} \mathrm{C}$ for $16 \mathrm{~h}$ with the primary antibody (rabbit antibody against glia fibrillary acidic protein, 1:80 (G9269); mouse monoclonal antibody against protein S100 $\beta$, 1:1000 (S2532); mouse monoclonal antibody against the cell proliferation antigen Ki-67, 1:800 (P6834)) was carried out. The sections were then treated with species specific secondary antibody (goat antibody against rabbit IgG, 1:400 (A9169); goat antibody against mouse IgG, 1:150 (A9917)) at room temperature for 1h and further, a complex of peroxidase anti-peroxidase (rabbit peroxidase anti-peroxidase (PAP) complex, 1:200 (P1291); mouse peroxidase anti-peroxidase (PAP) complex, 1:200 (P3039)). At the end of the procedure a tetrachloride 3,3'diaminobenzidine (30 $\mathrm{min}$ at room temperature) was used as chromogen. Subsequently, sections were rinsed in distilled $\mathrm{H}_{2} \mathrm{O}$, counterstained with Mayer's haematoxylin and mounted in DPX (Fluka, Buchs, Schwitzerland). At the same time a specificity controls for the immunohistochemical reactions were performed.

\section{Microscopic and statistical analyses}

The sections were examined and photographed under a light microscope Olympus BX-51 with an Olympus Color View IIIu digital camera. Microphotographs with a final magnification of $\times 400$ were archived. Next, 100 immunopositive and immunonegative for each of the three examined proteins derived from the 10 samples from each group of animals satellite glial cells were analysed using Cell ${ }^{\wedge} \mathrm{D}$ program. The data were presented as the mean number of cells with standard deviation. Significant differences $(P<0.05)$ between the means were shown by one-way ANOVA with post hoc Tukey test. All statistical analyses were performed using Statistica 8.0. 


\section{Results}

In all 63-day-old animals (groups C, 1, and 2) immunopositive reactions for GFAP in glial satellite cells were observed in the spinal ganglia. Numerous glia were immunoreactive for the examined protein $(51 \pm 6.27)$ in group 2 in comparison with the mean number of glia present in the spinal ganglia of group C $(28.6 \pm 8.1)$ (Plate I, Fig. 1A) and group 1 $(30.2 \pm 6.66)$ (Plate I, Fig. 1B). S-100 $\beta$-positive glia in the examined ganglia were numerous in group $1(34.8 \pm 5.83)$ and group $2(43.1 \pm 5.17)$, whereas only average numbers of them were found in control animals $(13 \pm 4.71)$. A cytoplasmic expression of $S-100 \beta$ protein in the satellite glial cells was observed in all rats. Additionally, the reaction product was seen in the nuclei of the examined glia in experimental animals (groups 1 and 2) (Plate I, Fig. 1D, Fig. 1E, Fig. 1F). Ki-67-immunopositive satellite glial cells were found in very small numbers in the spinal ganglia of all rats: group $\mathrm{C}(0.8 \pm 1.03)$, group $1(1.3 \pm 0.95)$, and group $2(1.6 \pm 0.7)$ (Plate I, Fig. 1C).

Morphometric analyses confirmed the results of microscopic examinations. Significant differences were demonstrated in the number of satellite glial cells expressing GFAP between group 2 and groups $\mathrm{C}$ and 1 which were comparable to each other, and in the number of S-100ß-positive glial cells between each group of animals $(\mathrm{C}, 1,2)$ (Fig. 2).

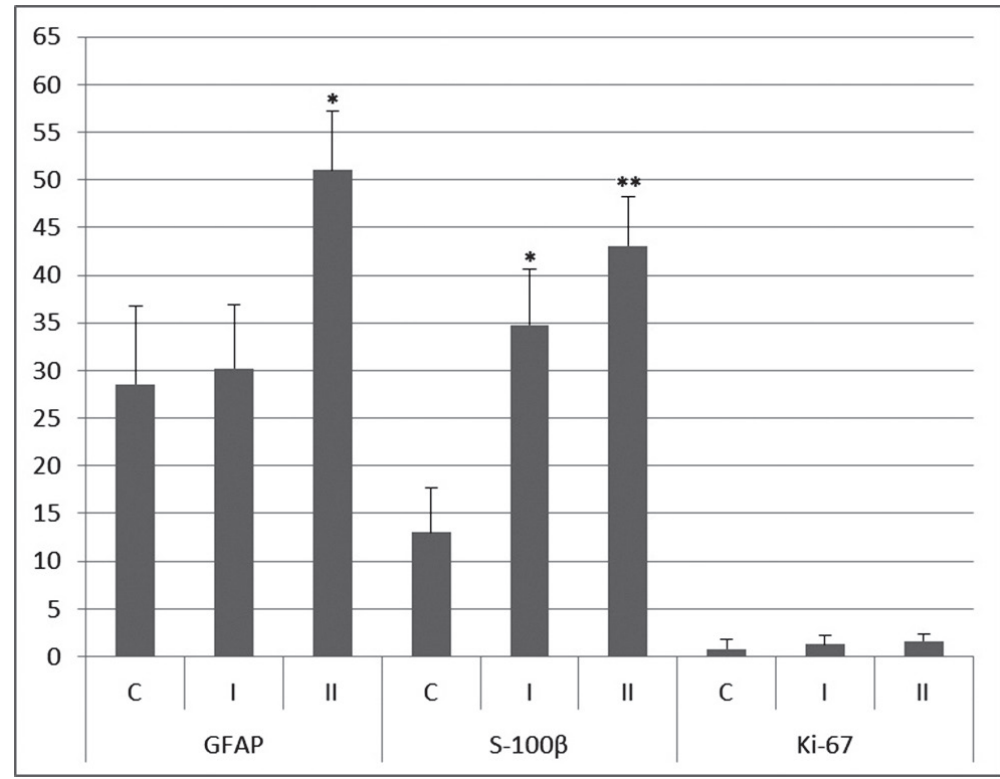

Fig. 2 The mean number of GFAP, S-100 3 and Ki-67-immunopositive cells of the spinal ganglia of 63-day-old control $(\mathrm{C})$ and experimental $(1,2)$ rats. Bars represent standard deviation; *, ** significant difference between groups of animals $(\mathrm{C}, 1,2)$ ANOVA $(P<0.05)$.

\section{Discussion}

Analyses conducted in this study showed an increase in the number of GFAP and S-100 immunopositive glia of the spinal ganglia of rats after treatment of MSG. The GFAP is a fibrillar protein that affects the shape of the cell and the structural stability of its processes. In addition, it binds to specific glutamate transporters. Hence the increased expression can be a result of the necessity to capture an excessive amount of neurotransmitters from the 
extracellular space (Sullivan 2014). The glia are actively involved in the metabolism of Glu due to the presence of both specific for the neurotransmitter membrane transporters as well as glutamine synthetase, an enzyme catalysing the conversion of glutamate to glutamine (Berger and Hediger 2000; Miller et al. 2002). Under physiological conditions, the GFAP is at a very low level in satellite glial cells (Ajima et al. 2001). An increased expression of this protein was observed after nerve damage and axotomy. In adult rats after the excision of a sciatic nerve fragment from the left thigh, six times more neurons surrounded by GFAP-immunopositive glial cells were demonstrated in the dorsal root ganglia in the operated side in comparison with the opposite side (Woodham et al. 1989).

Nucleo-cytoplasmic S-100 $\beta$ protein belongs to the calcium binding proteins from EF-hand family and reacts to changes in the level of calcium in the cell enabling the regulation of many internal and extracellular processes. S- $100 \beta$ influences the activity and metabolism of enzymes, phosphorylation of various proteins and the transcription of genes. Furthermore, this protein acts as a buffer lowering the intracellular concentration of calcium ions (Donato et al. 2009). An increased influx of these ions may be a consequence of the activation of specific receptors for Glu, which initiates a series of calcium-dependent enzymatic reactions. These processes can eventually lead to damage or death of cells (Mattson 2003; Platt 2007). In our study, the increased expression of the S-100 $\beta$ in the satellite glia may result from an increase of the intracellular calcium ion concentration and buffer properties of this protein to protect the cells. In addition, S-100 $\beta$ is actively released into the extracellular space, where it acts autocrinely and paracrinely on other cells. At nanomolar concentrations, it has a trophic effect on neural structures. It modulates Glu uptake by glial cells and also stimulates them to divide, thereby protecting the neurons from excitotoxicity (Selinfreund et al. 1991; Ahlemeyer et al. 2000; Rothermundt et al. 2003; Tramontina et al. 2006; Donato et al. 2009).

Increased division activity of satellite glial cells was observed after axotomy or inflammation of the sciatic nerve in rats (Hanani 2005). Cutting this nerve leads to damage of neurons, around which there are glia forming a multi-layer sheath in the shape of an onion bulb. The time required for the formation, however, is long. Between 43 and 65 days after axotomy, only $20 \%$ of the neurons were surrounded by this characteristic structure (Shinder et al. 1999; Hanani 2005). The proliferation of glia of the dorsal root ganglion was also demonstrated after the treatment of animals with organic compounds of mercury and lead. Satellite glial cells have the ability to uptake these substances in order to protect neurons. Long-term administration of lead acetate in rats leads to increased division activity, as well as hyperplasia of glial cells (Schlaepfer 1969; Schiønning and Danscher 1999). In our study, no increase in the number of Ki-67-immunoreactive nuclei after MSG treatment was observed, which most likely indicates too short duration of the experiment.

Analyses of the immunoreactivity of GFAP, S-100 $\beta$ protein and Ki-67 antigen in satellite glial cells allows us to specify the degree of advanced glial reactivity in response to the damaging factors to the structures of the nervous system. The analysis we carried out for the first time revealed an increase in the number of GFAP and S-100 $\beta$ immunoreactive structures in the dorsal root ganglia, indicating early glial reaction in response to increased levels of glutamate in the extracellular space. These changes are most likely due to the result of the cells' adaptation to altered environmental conditions that may adversely affect the structure and function of neurons. Such a reaction of the satellite glia may confirm its neuroprotective properties. Glial cells are likely to be involved in the course of pathological processes in the spinal ganglia and in the future, the determination of the nature and degree of their activation may thus create new directions for therapies of neurological diseases of the peripheral nervous system. 


\section{References}

Ahlemeyer B, Beier H, Semkova I, Schaper C, Krieglstein J 2000: S-100beta protects cultured neurons against glutamate- and staurosporine-induced damage and is involved in the antiapoptotic action of the 5 HT(1A)receptor agonist, Bay x 3702. Brain Res 858: 121-128

Ajima H, Kawano Y, Takagi R, Aita M, Gomi H, Byers MR, Maeda T 2001: The exact expression of glial fibrillary acidic protein (GFAP) in trigeminal ganglion and dental pulp. Arch Histol Cytol 64: 503-511

Berger UV, Hediger MA2000: Distribution of the glutamate transporters GLAST and GLT-1 in rat circumventricular organs, meninges, and dorsal root ganglia. J Comp Neurol 421: 385-399

Bezprozvanny I, Mattson MP 2008: Neuronal calcium mishandling and the pathogenesis of Alzheimer's disease. Trends Neurosci 31: 454-463

Donato R, Sorci G, Riuzzi F, Arcuri C, Bianchi R, Brozzi F, Tubaro C, Giambanco I 2009: S100B's double life: intracellular regulator and extracellular signal. Biochim Biophys Acta 793: 1008-1022

Eddleston M, Mucke L 1993: Molecular profile of reactive astrocytes-implications for their role in neurologic disease. Neuroscience 54: 15-36

Ganesan K, Sukalingam K, Balamurali K, Alaudeen SRBtS, Ponnusamy K, Ariffin IA, Gani SB 2013: A studies on monosodium L-glutamate toxicity in animal models- a review. IJPBCS 3: 1257-1268

Hanani M 2005: Satellite glial cells in sensory ganglia: from form to function. Brain Res Rev 48: 457-476

Kung LH, Gong K, Adedoyin M, Ng J, Bhargava A, Ohara PT, Jasmin L 2013: Evidence for glutamate as a neuroglial transmitter within sensory ganglia. PLOS ONE 8: e68312

Mallick HN 2007: Understanding safety of glutamate in food and brain. Indian J Physiol Pharmacol 51: $216-234$

Mattson MP 2003: Excitotoxic and excitoprotective mechanisms: abundant targets for the prevention and treatment of neurodegenerative disorders. Neuromolecular Med 3: 65-94

Middeldorp J, Hol EM 2011: GFAP in health and disease. Prog Neurobiol 93: 421-443

Miller KE, Richards BA, Kriebel RM 2002: Glutamine-, glutamine synthetase-, glutamate dehydrogenase- and pyruvate carboxylase immunoreactivities in the rat dorsal root ganglion and peripheral nerve. Brain Res 945: 202-211

Nedergaard M, Takano T, Hansen AJ 2002: Beyond the role of glutamate as a neurotransmitter. Nat Rev Neurosci 3: 748-755

Nörenberg MD 1994: Astrocyte responses to CNS injury. J Neuropathol Exp Neurol 53: 213-220

Ohara PT, Vit JP, Bhargava A, Romero M, Sundberg C, Charles AC, Jasmin L 2009: Gliopathic pain: when satellite glial cells go bad. Neuroscientist 15: 450-463

Platt SR 2007: The role of glutamate in central nervous system health and disease - a review. Vet J 173: 278-286

Rothermundt M, Peters M, Prehn JH, Arolt V 2003: S100B in brain damage and neurodegeneration. Microsc Res Tech 60: 614-632

Schiønning JD, Danscher G 1999: Autometallographic mercury correlates with degenerative changes in dorsal root ganglia of rats intoxicated with organic mercury. APMIS 107: 303-310

Schlaepfer WW 1969: Experimental lead neuropathy: a disease of the supporting cells in the peripheral nervous system. J Neuropathol Exp Neurol 28: 401- 418

Selinfreund RH, Barger SW, Pledger WJ, Van Eldik LJ 1991: Neurotrophic protein S100 beta stimulates glial cell proliferation. Proc Natl Acad Sci USA 88: 3554-3558

Shinder V, Govrin-Lippmann R, Cohen S, Belenky M, Ilin P, Fried K, Wilkinson HA, Devor M 1999: Structural basis of sympathetic-sensory coupling in rat and human dorsal root ganglia following peripheral nerve injury. J Neurocytol 28: 743-761

Stephenson JL, Byers MR 1995: GFAP immunoreactivity in trigeminal ganglion satellite cells after tooth injury in rats. Exp Neurol 131: 11-22

Sullivan SM 2014: GFAP variants in health and disease: stars of the brain... and gut. J Neurochem 130: 729-732

Tramontina F, Tramontina AC, Souza DF, Leite MC, Gottfried C, Souza DO, Wofchuk ST, Gonçalves CA 2006: Glutamate uptake is stimulated by extracellular S100B in hippocampal astrocytes. Cell Mol Neurobiol 26: 81-86

Woodham P, Anderson PN, Nadim W, Turmaine M 1989: Satellite cells surrounding axotomised rat dorsal root ganglion cells increase expression of a GFAP-like protein. Neurosci Lett 98: 8-12

Yuan H, Zheng JC, Liu P, Zhang SF, Xu JY, Bai LM 2007: Pathogenesis of Parkinson's disease: oxidative stress, environmental impact factors and inflammatory processes. Neurosci Bull 23: 125-130 
Plate I

Krawczyk A. E. et al.: The immunoreactivity... pp. 337-341
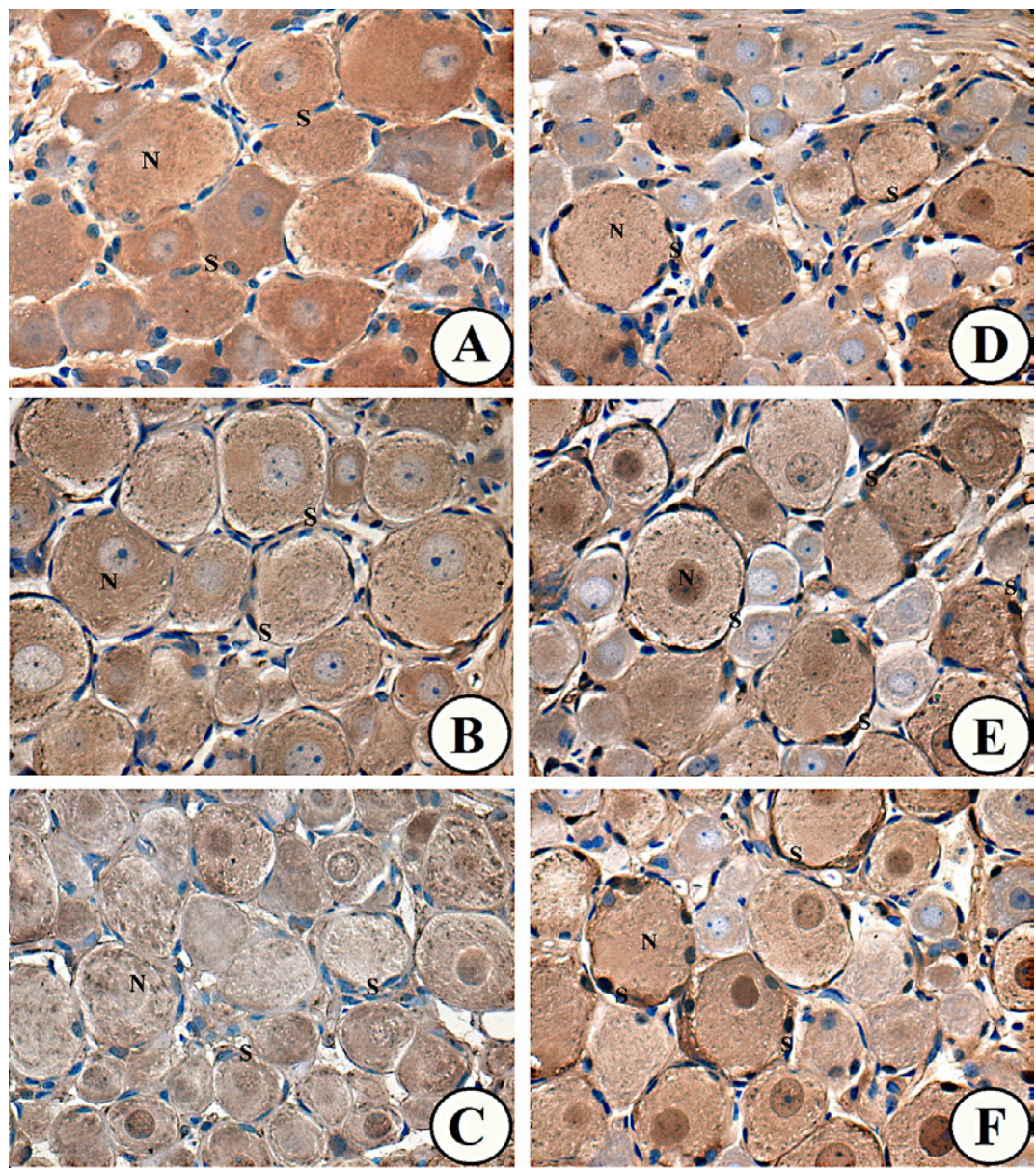

Fig. 1 GFAP (A, B), S100ß (D, E, F) and Ki-67 (C) immunoreactive satellite glial cells of the spinal ganglia of 63-day-old control rats (A, D) and those treated with MSG in group 1 (E) and group 2 (B, C, F). (S) - satellite glial cells, (N) - neurons. Magnification approximately $\times 400$ 